\title{
Children and Adolescent Perfectionism Scale: Validation in a Portuguese Adolescent Sample
}

\author{
Escala de Perfecionismo de Crianças e Adolescentes: Validação \\ em Adolescentes Portugueses
}

\author{
Carmen Bento*, Ana Telma Pereira, Jorge Manuel Saraiva \& António Macedo \\ University of Coimbra, Coimbra, Coimbra District, Portugal
}

\begin{abstract}
The aim of this study was to analyze the psychometric properties of the Portuguese version of the Child and Adolescent Perfectionism Scale (CAPS). Method: 971 Portuguese high school students (572 girls and 399 boys) answered the CAPS. The test-retest reliability was obtained with 206 participants from the total sample. Results: Internal consistency $(\alpha=.809)$ and test-retest reliability $(r=.691)$ were satisfactory. Main components of factorial analysis yielded two factors, accounting for $41.44 \%$ of the total variance. Factor structure was similar to the original version. Factors were labelled as "Socially Prescribed Perfectionism" and "Self-Oriented Perfectionism". Discussion: The Portuguese version of the CAPS is a valid and useful instrument for the evaluation of perfectionism among Portuguese adolescents.

Keywords: CAPS, validation, adolescents, perfectionism.

Resumo

O objetivo do estudo foi analisar as propriedades psicométricas da "Child and Adolescent Perfectionism Scale - CAPS” (Escala de Perfecionismo de Crianças e Adolescentes - EPCA). Método: 971 adolescentes portugueses do ensino secundário (572 raparigas e 399 rapazes) responderam a EPCA. A estabilidade temporal foi obtida com 206 participantes da amostra total. Resultados: A consistência interna $(\alpha=0,809)$ e a estabilidade temporal $(r=0,691)$ foram satisfatórias. A análise fatorial dos principais componentes produziu dois fatores, que explicou $41,44 \%$ da variância total. A estrutura fatorial foi semelhante à da versão original. Os fatores foram denominados "Perfecionismo Socialmente Prescrito" e "Perfecionismo Auto-orientado". Discussão: A versão portuguesa da "CAPS"é um instrumento válido e útil para a avaliação do Perfecionismo em adolescentes portugueses.

Palavras-chave: EPCA, validação; adolescentes; perfecionismo
\end{abstract}

Perfectionism is a complex construct characterized by the setting of and striving for unrealistic personal standards, a tendency toward critical self-evaluation if these standards are not reached, excessive concern over mistakes, doubts about the quality of personal achievement, and excessive emphasis on precision and organization (Flett \& Hewitt, 1991). Empirical investigation of perfectionism has been increased dramatically in recent years (Flett \& Hewitt, 2002).

Perfectionism was first conceptualized as an unidimensional construct (Burns, 1980), but currently, perfectionism is constructed as a multidimensional concept having both personal and social components (Frost, Marten, Lahart, \& Rosenblate, 1990; Hewitt \& Flett, 1991; Rice \& Preusser, 2002). Not only in adults but also in children, Socially Prescribed Perfectionism

\footnotetext{
Mailing Address: University Clinic of Pediatrics, Pediatric Hospital Carmona da Mota, Quinta Rainha, Coimbra, Portugal 3020-189. E-mail: carmenbento@sapo.pt
}

The co-operation of the Professors and Students is gratefully acknowledged.
(SPP) is considered to be more maladaptative and SelfOriented Perfectionism (SOP) is a more adaptative construct (Hewitt et al., 2002). Perfectionism is associated with psychological distress in clinical and non clinical populations. Several studies have verified the relationship between Perfectionism and psychopathology in children and adolescents: eating disorders (Castro et al., 2004; Castro-Fornieles et al., 2007), depression (Huggins, Davis, Rooney, \& Kane, 2008); anxiety and self harm (R. C. O'Connor, Rasmussen, \& Hawton, 2010); obsessive compulsive disorder (Libby, Reynolds, Derisley, \& Clark, 2004); rumination (Flett, Coulter, Hewitt, \& Nepon, 2011); fear and sadness (Stornelli, Flett, \& Hewitt, 2009).

There are three validated self-report questionnaires to measure multidimensional Perfectionism in adolescence: (a) the Multidimensional Perfectionism Scale (MPS) is a 45-item scale that assesses SOP (i.e., unrealistic standards and perfectionistic motivation for the self), other-oriented perfectionism (i.e., unrealistic standards and perfectionistic motivations for others), and SPP (i.e., the belief that significant others expect oneself to be perfect); this fac- 
Bento, C., Pereira, A. T., Saraiva, J. M. \& Macedo, A. (2014). Children and Adolescent Perfectionism Scale: Validation in a Portuguese Adolescent Sample.

tor structure is congruent across clinical and subclinical populations (MPS; Hewitt \& Flett, 1991). There is a MPS adapted version to be used with children and adolescents, the Child and Adolescent Perfectionism Scale. It is distinguished from the MPS because it comprises only two subscales rather than three: SPP and SOP (CAPS; Flett \& Hewitt, 2002; Flett, Hewitt, Boucher, Davidson, \& Munro, 2001); (b) the Frost Multidimensional Perfectionism Scale (FMPS; Frost et al., 1990) provides six subscales for a multidimensional assessment of perfectionism: Concern over Mistakes, Personal Standards, Parental Expectations, Parental Criticism, Doubts about actions, and Organization; (c) the Almost Perfect Scale-Revised (APS-R; Slaney, Rice, Mobley, Trippi, \& Ashby, 2001) measures three dimensions of personal perfectionism: High Standards, Order and Discrepancy.

The CAPS is the instrument that has been more used for evaluating Perfectionism in children and adolescents in a variety of cultures and samples (AbdulKader \& Eissa, 2012; Castro et al., 2004; R. C. O’Connor, Dixon, \& Rasmussen, 2009). In Portugal, the MPS has been validated in adults (Soares, Gomes, Macedo, Santos, \& Azevedo, 2003) and the experimental version of the CAPS was already used once in adolescents (Bento et al., 2010). However, the scale has not been validated in a Portuguese child and adolescent population.

The original CAPS was developed from Hewitt and Flett's (1991) original MPS. It is a well-established 22item scale distinguished from MPS because it comprises two subscales rather than three: SPP- Socially Prescribed Perfectionism (10 items e.g. "There are people in my life who expect me to be perfect") and SOP-Self Oriented Perfectionism (12 items e.g. "I try to be perfect in everything I do"). From those studies that have used the CAPS, there is evidence that Perfectionism is associated with psychological distress and maladjustment in children and adolescence (Castro et al., 2004; Donaldson, Spirito, \& Farnett, 2000; Flett \& Hewitt, 2002). The original CAPS showed adequate test-retest reliability (SOP: $r=.74$ and SPP: $r=.66$ ) and good internal reliability (SOP: $\alpha=.85$; SPP, $\alpha=.81$; Flett et al., 2001).

In the Portuguese study where the experimental version of the CAPS was used (Bento et al., 2010), we verified that perfectionism was significantly associated with dysfunctional eating behaviours in adolescents. To our knowledge there is not any Portuguese language version of the CAPS. Given this we considered that the adaptation and validation of the scale into Portuguese would fill an important gap and it could be very useful in both clinic and research fields.

\section{Method}

\section{Subjects}

Nine hundred and seventy-one adolescents, 572 girls (59\%) and 399 boys (41\%), from four secondary schools in the urban area of Coimbra, Portugal, participated in the study. The schools were randomly selected, so that all social and cultural backgrounds were represented. The mean age was 15.80 years $(S D=1.509)$ with no statistically significant differences between genders (572 girls vs. 399 boys: $M=15.77 \pm 1.559$ vs. $M=15.84 \pm 1.436, p=.500)$.

\section{Measures}

Child and Adolescent Perfectionism Scale (CAPS). The Child and Adolescent Perfectionism Scale is a 22 items scale. It comprises two subscales: SPP - Socially Prescribed Perfectionism (10 items) and SOP - Self Oriented Perfectionism (12 items). Responders rated each statement on a 5-point Likert-type scale ranging from 1 (false-not at all true for me) to 5 (very true for me). CAPS scores can range from 1 to 110 . Items 3, 9 and 18 from the CAPS were reversed to ensure that a higher score indicated greater Perfectionism for all items. The original version was translated into Portuguese by the research group. The back translation, technical review and semantic evaluation and pre-test were made by specialists in development of self-report questionnaires. Preliminary qualitative item analysis included the thinking aloud methodology with pilot participants. The final version yielded total overlap with the English original version.

\section{Procedure}

Permission was obtained from the Ethic Commission of Faculty of Medicine of Coimbra, from the Portuguese Data Protection Authority and from the schools headmasters. The informed consent was also obtained from the parents of the adolescents who took part. Confidentiality was ensured. To study the temporal stability 206 respondents (124-60\% girls and $82-40 \%$ boys) answered the questionnaires in two different moments separated by approximately five weeks.

\section{Results}

\section{Internal Reliability}

The total internal consistency coefficient (Cronbach - $\alpha$ ) was of .81. Pearson correlation coefficients between each item and the total score (excluding the item) ranged from .83 (item 18) to .78 (item 13). According to Cohen's criteria (1992), the magnitude of the item-total correlations were moderate $(>.30)$ or high $(>.50)$. Only three items showed correlations $\leq .30$ with the corrected total (items $3,4,9)$. These items plus item $18(\alpha=83)$ would have the effect of maintaining or elevating the scale internal reliability.

\section{Test-Retest Reliability}

Temporal stability was analysed by the test-retest correlation method (Pearson correlation). Two hundred and six adolescents answered the scale five weeks later. For the Portuguese version of the CAPS, the correlation coefficient was of .69 $(p<.001)$ for the total score. For SPP it was of $.69(p<.001)$ and for SOP it was of $.59(p<.001)$ 


\section{Factor Analysis}

The 22 items of the CAPS were subjected to a principal components analysis. The suitability of the data for factor analysis was assessed. The Kaiser-Meyer-Oklin value was of .90. Principal components analysis revealed the presence of four components with eigenvalues exceeding 1, explaining $52.38 \%$ of the total variance. An inspection of the Cattel's Scree plot and also of the item's content/ interpretability led us to select a two factors structure that explained $41.44 \%$ of the variance (Table 1 ).
Factor 1 was labelled 'Socially Prescribe Perfectionism' ( 10 items; $\alpha=.86$ ) and explains $20.99 \%$ of the variance. The second factor was labelled 'Self Oriented Perfectionism' ( 12 items; $\alpha=.83$ ) and explains $20.45 \%$ of the variance. The factor's $\alpha$ were very good, considering the number of items (Table 1). The parallel analysis using Monte Carlo algorithms (Rosenthal, 2000) generated three factors structure. However, the third component of the three factors solution was composed of items 3,9 and 18, which was unintelligible.

Table 1

CAPS Factor Structure

\begin{tabular}{|c|c|c|}
\hline EPCA & Items & $\begin{array}{l}\text { Loadings } \\
\qquad(\alpha)\end{array}$ \\
\hline \multirow{10}{*}{$\begin{array}{l}\text { Factor I } \\
\text { Socially Prescribed } \\
\text { Perfectionism }\end{array}$} & 13. Other people always expect me to be perfect. & .806 \\
\hline & 8. My family expects me to be perfect. & .760 \\
\hline & 15. People around me expect me to be great at everything. & .751 \\
\hline & 5. There are people in my life who expect me to be perfect & .706 \\
\hline & 21. I feel that people ask too much of me. & .680 \\
\hline & 19. I am always expected to do better than others. & .623 \\
\hline & 12. Other people think that I have failed if I do not do my best all the time. & .613 \\
\hline & 10. People expect more from me than I am able to give. & .601 \\
\hline & 17. My teachers expect my work to be perfect. & .490 \\
\hline & 3. My parents don't always expect me to be perfect in everything I do. & -.312 \\
\hline \multirow{12}{*}{$\begin{array}{l}\text { Factor II } \\
\text { Self Oriented } \\
\text { Perfectionism }\end{array}$} & 2. I want to be the best at everything I do. & .724 \\
\hline & 16. When I do something, it has to be perfect. & .708 \\
\hline & 1. I try to be perfect in everything I do. & .706 \\
\hline & 7. It really bothers me if I don't do my best all the time. & .652 \\
\hline & 6. I always try for the top score on a test. & .632 \\
\hline & 14. I get upset if there is even one mistake in my work. & .627 \\
\hline & 9. I don't always try to be the best. & -.576 \\
\hline & $\begin{array}{l}\text { 20. Even when I pass, I feel that I have failed if I didn't get one of the highest marks } \\
\text { in the class. }\end{array}$ & .552 \\
\hline & 18. I do not have be the best at everything I do. & -.494 \\
\hline & 11. I get mad at myself when I make a mistake. & .409 \\
\hline & 22.I can't stand to be less than perfect & .392 \\
\hline & 4. I fell that I have to do my best all the time. & .361 \\
\hline
\end{tabular}

Note. $\alpha=$ Cronbach alpha.

\section{Discussion}

This study presents the validation of the CAPS questionnaire in a large representative sample of Portuguese adolescents. We examined the 22 item version, reversing items 3, 9 and 18. The Portuguese CAPS properties are good. The two factors account for $41.44 \%$ of the total variance. The number of factors and their composition were identical to that obtained for the original version (Hewitt, Newton, Flett, \& Callender, 1997), the Spanish version (Castro et al., 2004) and the Arabic version (AbdulKader \& Eissa, 2012). These results support the 
Bento, C., Pereira, A. T., Saraiva, J. M. \& Macedo, A. (2014). Children and Adolescent Perfectionism Scale: Validation in a Portuguese Adolescent Sample.

multidimensional construct of Perfectionism in Portuguese adolescents, consistent with previous studies conducted in different cultures (Cheng, Chong, \& Wong, 1999; Enns, Cox, \& Clara, 2002). Some researches (McCreary, Joiner, Schmidt, \& Ialongo, 2004; R. C. O’Connor et al., 2009), recently presented a 3 factors structure of the CAPS: the SOP-Striving and SOP-Critical. In our Portuguese sample, a three factors structure was also analysed, but it was not interpretable. B. P. O'Connor (2000) refers that optimal decisions are thus likely to be made after the results of both analytic procedures have been considered. Considering the both analytic procedure, the two factor solution was better than three factor solution.

The internal reliability of the total CAPS $(\alpha=.81)$, the SPP $(\alpha=.85)$ and the SOP $(\alpha=.83)$ were very good (Devellis, 1991) and quite similar to the figures obtained with the original version (SOP: $\alpha=.85$; SPP, $\alpha=.81$; Flett et al., 2001). This finding is important to support the validity of the CAPS subscales in different cultures (Bass $\&$ Siyez, 2010). The interval between test and re-test was appropriate for personality instruments (Loewenthal, 2001). The temporal stability reliability (SOP: $r=.69$ and SPP: $r=.59$ ) were also comparable to the original (SOP: $r=.74$ and SPP: $r=.66$; Hewitt et al., 1997) and others versions recently validated (SOP: $r=.63$ and SPP: $r=.72$ Bass \& Siyez, 2010; SOP-Critical: $r=.65$, SOP-Striving: $r=.64$ and SPP: $r=.61$; R. C. O'Connor et al., 2009).

The principal limitation of the present study is the fact that our sample did not include children. In a near future, the authors pretend to validate the CAPS in a younger sample and continuing studding Perfectionism in adolescents and children.

In conclusion, the Portuguese version of the CAPS is an adequate instrument for measuring Perfectionism in Portuguese adolescents. Furthermore, being the Portuguese language spoken by more than 223 million people located in nine countries, this instrument could be useful across the globe.

\section{References}

AbdulKader, F. A., \& Eissa, M. A. (2012). Psychometric properties of the Arabic version of the Child and Adolescent Perfectionism Scale in a sample of Egyptian adolescents. Islamic Association for Human Cognition Magazine, 1, 1-7.

Bass, A. U., \& Siyez, D. M. (2010). Adaptation of the Child and Adolescent Perfectionism Scale to Turkish: The validity and reliability study. Elementary Education Online, 9(3), 898-909.

Bento, C., Pereira, A. T., Maia, B., Marques, M., Soares, M. J., Bos, S., ...Macedo, A. (2010). Perfectionism and eating behavior in Portuguese adolescents. European Eating Disorders Review, 18(4), 328-337. doi:10.1002/erv.981

Burns, D. D. (1980). The perfectionist script for self-defeat. Psychology Today, 41, 34-51.

Castro, J., Gila, A., Gual, P., Lahortiga, F., Saura, B., \& Toro, J. (2004). Perfectionism dimensions in children and adolescents with anorexia nervosa. Journal of Adolescent Health, 35, 392-398. doi:10.1037/a0016264
Castro-Fornieles, J., Gual, P., Lahortiga, F., Gila, A., Casulà, V., Fuhrmann, C., ...Toro, J. (2007). Self-oriented perfectionism in eating disorders. International Journal of Eating Disorders, 40(6), 562-568. doi:10.1002/eat.20393

Cheng, S. K., Chong, G. H., \& Wong, C. W. (1999). Chinese Frost Multidimensional Perfectionism Scale: A validation and prediction of self-esteem and psychological distress. Journal of Clinical Psychology, 55, 1051-1061.

Cohen, J. (1992). A power primer. Psychological Bulletin, 112, 155-159.

Donaldson, D., Spirito, A., \& Farnett, E. (2000). The role of perfectionism and depressive cognitions in understanding the hopelessness experienced by adolescent suicide attempters. Child Psychiatry \& Human Development, 31(2), 99-111. doi:10.1023/A:1001978625339

Enns, M. W., \& Cox, B. (2002). The nature and assessment of perfectionism: A critical analysis. In G. L. Flett \& P. L. Hewitt (Eds.), Perfectionism: Theory, research, and treatment (pp. 5-30). Washington, DC: American Psychological Association.

Flett, G. L., Coulter, L. M., Hewitt, P. L., \& Nepon, T. (2011). Perfectionism, rumination, worry, and depressive symptoms in early adolescents. Canadian Journal of School Psychology, 26(3), 159-176. doi:10.1177/0829573511422039

Flett, G. L., \& Hewitt, P. L. (1991). Perfectionism in the self and social context: Conceptualization, assessment, and association with psychopathology. Journal of Personality and Social Psychology, 60, 456-470. Retrieved from hewittlab. psych.ubc.ca/pdfs/1991hf2.pdf

Flett, G. L., \& Hewitt, P. L. (2002). Perfectionism and maladjustment: An overview o theoretical, definitional, and treatment issues. In Perfectionism: Theory, research and treatment (pp. 5-31). Washington, DC: American Psychological Association.

Flett, G. L., Hewitt, P. L., Boucher, D. J., Davidson, L. A., \& Munro, Y. (2001). The Child and Adolescent Perfectionism Scale: Development, validation, and association with adjustment. Unpublished manuscript, Department of Psychology, University of Columbia, Canada.

Frost, R., Marten, P., Lahart, C., \& Rosenblate, R. (1990). The dimensions of perfectionism. Cognitive Therapy and Research, 14, 449-468.

Hewitt, P. L., Caelian, C. F., Flett, G. L., Sherry, S. B., Collins, L., \& Flynn, C. A. (2002). Perfectionism in children: Associations with depression, anxiety and anger. Personality and Individual Differences, 32, 1049-1061. Retrieved from http://www.sciencedirect.com/science/article/pii/ S019188690100109X?via=ihub

Hewitt, P. L., \& Flett, G. L. (1991). Perfectionism in the self and social contexts: Conceptualization, assessment, and association with psychopathology. Journal of Personality and Social Psychology, 60(3), 456-470. doi:10.1037/0022-3514.60.3.456

Hewitt, P. L., Newton, J., Flett, G. L., \& Callender, L. (1997). Perfectionism and suicide ideation in adolescent psychiatric patients. Journal of Abnormal Child Psychology, 25, 95-101. Retrieved from http://link.springer. com/10.1023/A:1025723327188

Huggins, L., Davis, M. C., Rooney, R., \& Kane, R. (2008). Socially prescribed and self-oriented perfectionism as predictors of depressive diagnosis in preadolescents. Australian Journal of Guidance and Counseling, 18, 182-194.

Libby, S., Reynolds, S., Derisley, J., \& Clark, S. (2004). Cognitive appraisals in young people with obsessive-compulsive disorder. Journal of Child Psychology and Psychiatry, 45, 1076-1084. doi:10.1111/j.1469-7610.2004.t01-1-00300.x 
Loewenthal, K. M. (2001). An introduction to psychological tests and scales ( $2^{\text {nd }}$ ed.). London: Psychology Press.

McCreary, B. T., Joiner, T. E., Schmidt, N. B., \& Ialongo, N. S. (2004). The structure and correlates of perfectionism in African American children. Journal of Clinical Child and Adolescent Psychology, 33, 313-324. doi:10.1037/a0016264

O'Connor, B. P. (2000). SPSS and SAS programs for determining the number of components using parallel analysis and Velicer's MAP Test. Behavior Research Methods, Instruments, \& Computers, 32(3), 396-402.

O'Connor, R. C., Dixon, D., \& Rasmussen, S. (2009). The structure and temporal stability of the Child and Adolescent Perfectionism Scale. Psychological Assessment, 21, 437-443. doi:10.1037/a0016264

O'Connor, R. C., Rasmussen, S., \& Hawton, K. (2010). Predicting depression, anxiety and self-harm in adolescents: The role of perfectionism and acute life stress. Behaviour Research and Therapy, 48, 52-59. doi:10.1016/j.brat.2009.09.008

Rice, K. G., \& Preusser, K. J. (2002). The Adaptative / Maladaptative Perfectionism Scale. Measurement and Evaluation in Counseling and Development, 34(4), 210-222.

Rosenthal, J. (2000). Parallel computing and Monte Carlo algorithms. Far East Journal of Theoretical Statistics, 4, 207-236.

Slaney, R. B., Rice, K. G., Mobley, M., Trippi, J., \& Ashby, J. S. (2001). The revised Almost Perfect Scale. Measurement and Evaluation in Counseling and Development, 34, 130-145.

Soares, M. J., Gomes, A. A., Macedo, A. F., Santos, V., \& Azevedo, M. H. (2003). Escala Multidimensional do Perfeccionismo: Adaptação à população portuguesa. Revista Portuguesa de Psicossomática, 5(1), 46-55.

Stornelli, D., Flett, G., \& Hewitt, P. (2009). Perfectionism, achievement, and affect in children: A comparison of students from gifted, arts, and regular programs. Canadian Journal of School Psychology, 24, 267-283. doi:10.1177/0829573509342392 